San Jose State University

SJSU ScholarWorks

Master's Theses

Master's Theses and Graduate Research

1989

\title{
Effects of shift rotation on mood in those defined as morning or evening types
}

Margaret Hughes Carney

San Jose State University

Follow this and additional works at: https://scholarworks.sjsu.edu/etd_theses

\section{Recommended Citation}

Carney, Margaret Hughes, "Effects of shift rotation on mood in those defined as morning or evening types" (1989). Master's Theses. 3058.

DOI: https://doi.org/10.31979/etd.pwbq-4m9s

https://scholarworks.sjsu.edu/etd_theses/3058

This Thesis is brought to you for free and open access by the Master's Theses and Graduate Research at SJSU ScholarWorks. It has been accepted for inclusion in Master's Theses by an authorized administrator of SJSU ScholarWorks. For more information, please contact scholarworks@sjsu.edu. 


\section{INFORM̃ATIONN TO USERS}

The most advanced technology has been used to photograph and reproduce this manuscript from the microfilm master. UMI films the text directly from the original or copy submitted. Thus, some thesis and dissertation copies are in typewriter face, while others may be from any type of computer printer.

The quality of this reproduction is dependent upon the quality of the copy submitted. Broken or indistinct print, colored or poor quality illustrations and photographs, print bleedthrough, substandard margins, and improper alignment can adversely affect reproduction.

In the unlikely event that the author did not send UMI a complete manuscript and there are missing pages, these will be noted. Also, if unauthorized copyright material had to be removed, a note will indicate the deletion.

Oversize materials (e.g., maps, drawings, charts) are reproduced by sectioning the original, beginning at the upper left-hand corner and continuing from left to right in equal sections with small overlaps. Eâch original is also photographed in one exposure and is included in reduced form at the back of the book. These are also available as one exposure on a standard 35mm slide or as a 17" x 23" black and white photographic print for an additional charge.

Photographs included in the original manuscript have been reproduced xerographically in this copy. Higher quality $6^{\prime \prime} \times 9^{\prime \prime}$ black and white photographic prints are available for any photographs or illustrations appearing in this copy for an additional charge. Contact UMI directly to order.

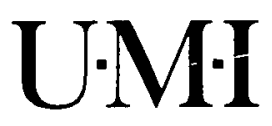

University Microfilms International

A Bell \& Howell Information Company 300 North Zeeb Road, Ann Arbor, MI 48106-1346 USA 
Order Number 1337 791

Effects of shift rotation on mood in those defined as morning and evening types

Carney, Margaret Hughes, M.A.

San Jose State University, 1989

Copyright (C1990 by Carney, Margaret Hughes. All rights reserved.

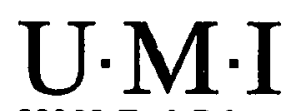

300 N. Zeeb Rd.

Ann Arbor, MI 48106 


\title{
EFFECTS OF SHIFT ROTATION ON MOOD IN THOSE DEFINED AS MORNING AND EVENING TYPES
}

\author{
A Thesis \\ Presented to \\ The Faculty of the Department of Psychology \\ San Jose State University
}

In Partial Fulfillment

of the Requirements for the Degree

Master of Arts

\author{
by \\ Margaret Hughes Carney \\ May, 1989
}




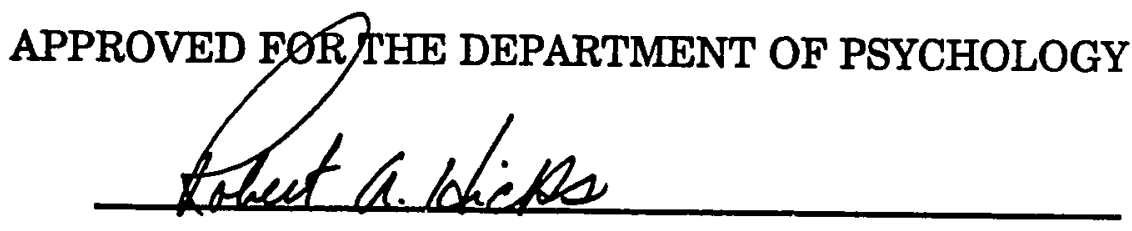

Robert Hicks Ph.D

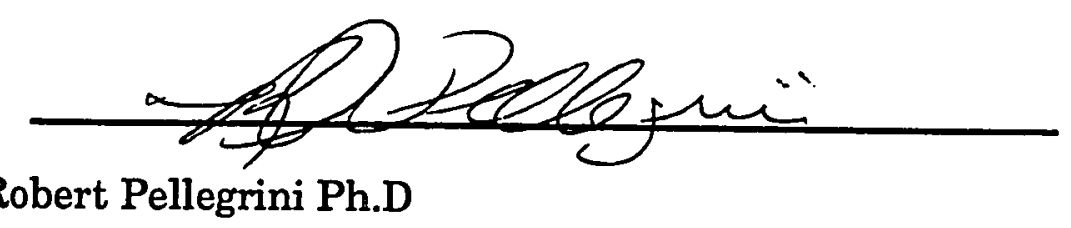

Robert Pellegrini Ph.D

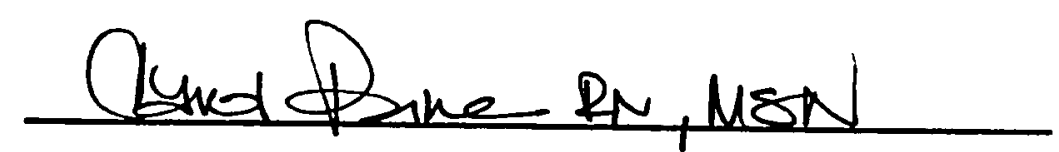

Carol Paine R.N., M.S.N.

APPROVED FOR THE UNIVERSITY

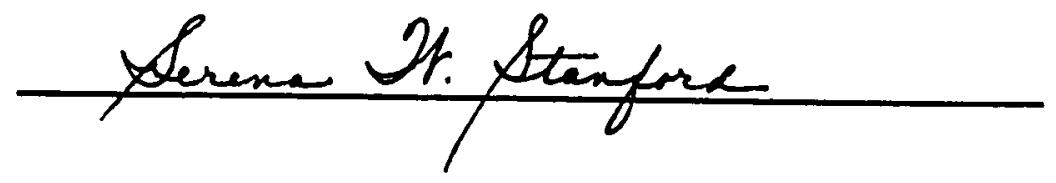




\section{TABLE OF CONTENTS}

SECTION

PAGE

INTRODUCTION

STATEMENT OF PROBLEM................................................. 4

Hypothesis 1

Hypothesis 2

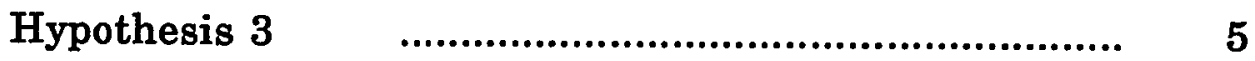

LITERATURE REVIEW................................................... 6

Morning and Evening Types $\quad$.................................. 6

Shift Work and Health $\quad$........................................... 7

Length of Sleep $\quad$................................................... 9

METHOD.............................................................. 10

Research Participants $\quad$........................................... 10

MEASURES............................................................ 11

Morning and Evening Types $\quad$.................................. 11

Mood $\quad$...................................................................... 11

Sleep Duration $\quad$...................................................... 12

DESIGN................................................................... 12

RESULTS................................................................ 13

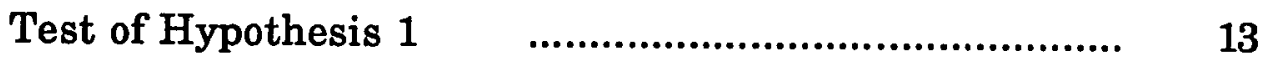

Test of Hypothesis 2

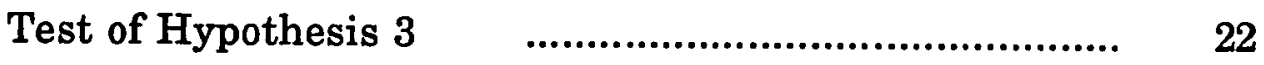

DISCUSSION.............................................................

REFERENCES.................................................... 28

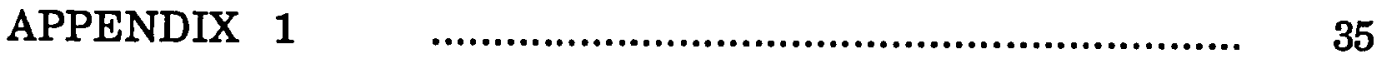

APPENDIX $2 \quad$....................................................... 40 


\section{LIST OF TABLES}

TABLE

PAGE

1. Means and Standard Deviations for Morning and Evening Types $\quad$................................................ 14

2. Confusion--Bewilderment Scale...................................... 16

3. Fatigue--Inertia Scale................................................ 17

4. Tension--Anxiety Scale................................................. 18

5. Anger--Hostility Scale................................................ 19

6. Depression--Dejection Scale............................................. 20

7. Vigor--Activity Scale........................................................ 21

8. Means and Standard Deviations for Hours of Sleep in Morning and Evening Types, and Sleep Satisfaction Rating 
Mood \& Shift Rotation

\author{
Effects of Shift Rotation on Mood in \\ Those Defined as Morning and Evening Types \\ Margaret Hughes Carney \\ San Jose State University
}

Running head: EFFECTS OF SHIFT ROTATION ON MOOD 
Mood \& Shift Rotation

\begin{abstract}
It was hypothesized that certain dimensions of personality (morning and evening types) might predict adaptability to rotating shift work as measured by indices of psychological mood states. Fifty rotating shift nurses were identified as either morning or evening types by the Ostberg Scale. The hypothesis that morning types would score significantly higher in mood disruption while working the evening / night shifts, as well as the hypothesis that evening types would be more disrupted in mood while working day shifts was not supported. Morning types (80\%) reported more satisfaction with their sleep when working days than did evening types (60\%). The mean difference between between day and evening shifts is greater for morning types $(t(26)=4.29, p<.001)$ than evening types $(t(26)=2.55, p<.02)$. Rotating shift nurses may not be sleep deprived when working the evening / night shift as reported in other studies.
\end{abstract}


Mood \& Shift Rotation

Effects Of Shift Rotation On Mood

In Those Defined As Morning And Evening Types

The theory of morningness-eveningness which postulates there are "morning type" people and "evening type" people, was first proposed by Kleitman in 1963. Kleitman found different peak body temperatures in individuals which he then classified as either morning or evening types. Using a scale they developed to measure these types, Horne and Ostberg (1976) found a significant correlation between oral temperature, arising, and bed times. Their morning types showed a steep temperature rise in the morning with an early peak (68 minutes after arising). Their evening type subjects started with a lower body temperature, which gradually raised during the day, and then declined towards the middle of the evening. In a second study, Horne and Ostberg (1977) found that morning types have a larger temperature amplitude than evening types. After reviewing these data, Taub, Hawkins and Van de Castle (1978) concluded that because morning types have phase advanced temperature rhythms, their temperatures peak earlier than evening types. Thus, morning types suffer more sleep disturbances when they work night shifts. Consistent with this pattern, morning types typically report earlier bedtimes and earlier arising times than evening types (Mecacci \& Zani, 1983).

Since the introduction into the literature of the terms morning type and evening type, several studies have identified distinctions between them. For example, differences between these two types have been reported for food intake (Ostberg, 1973), certain psychological tests (Patikai, 1970), and 
subjective alertness (Patkai, 1971a). In addition, significant correlations between morningness and introversion, and between eveningness and extroversion, were computed by Patkai (1971b). In this regard, Colquhoun and Folkard (1978) suggested that neurotic extroverts resemble evening types in that their temperature rhythms exhibit a greater degree of adjustment than those of introverts. Finally, Winget, DeRoshia, Markley, and Holley (1984) suggested that subjects who display small amplitudes in their body temperature rhythm show less resistance to phase shift. Because of the temperature amplitude differences noted, these data suggest that the behavior of evening types when working night / evening shifts will be less affected than the behavior of morning types.

\section{Statement of the Problem}

As is evident in the literature review, rotating shift work poses a greater health hazard to workers than those on fixed shift systems. Considerable research has been published on the fluctuations of the circadian rhythms in shift workers. Collectively, these data show that the harmful effects of shift work result from disturbances to physiological and psychological functions which may be linked to individual circadian cycles. In shift work (especially the night shift), people work hours which are often in conflict with their established temperature and sleep cycles. The ability to adapt to a new cycle varies for each individual. However, it may be that certain dimensions of personality (e.g., morning and evening types) might predict adaption level to rotating shift work as measured by indices of psychological mood states. In this regard, it is plausible to assume that evening type 
Mood \& Shift Rotation

people would adapt more readily to rotating shift work than their morning type peers. Thus, the following hypotheses were tested in this study. Hypothesis 1

Morning types will experience significantly greater difficulty adapting to night shift work than evening types resulting in mood disruption as measured by the Profile of Mood States (POMS) (McNair, Lorr, \& Droppleman, 1971) on these five POMS scales: confusion, anxiety, anger, depression, and fatigue. Conversely, evening types will experience greater mood disruption and score higher than morning types on the same scales when they are working the day shift.

\section{Hypothesis 2}

While working nights or evenings, morning types will be more disrupted by evening or night work than evening types, and will score lower than evening types on the vigor scale of the POMS. Conversely, evening types will score lower on the vigor scale when working the day shift than morning types.

\section{Hypothesis 3}

The length and quality of sleep while working nights or evenings will be affected more for morning types than for evening types. Morning types will be less satisfied and sleep less when working night / evening shifts than evening types.

\section{Literature Review}

\section{Morning and Evening Types}

In a 1973 study, Ostberg concluded that the night shift was the most 
Mood \& Shift Rotation

difficult adjustment to make and that morning types had more difficulty adapting to shift work than did evening types. In elaborating this conclusion, Ostberg claimed morning types are not able to adapt their sleep habits to the needs of shift work as readily as evening types. In this regard, he noted morning types have a more autonomous circadian rhythm than evening types. Folkard, Monk and Lobban (1978) reported the ability to adjust well to shift work was contingent upon morningness / eveningness status, flexibility of sleep patterns, and the individual's ability to overcome drowsiness. Tepas and Mahan (1986) studied workers who preferred the permanent night shift and found that within this group evening types were the majority and that they reported fewer sleep difficulties when working the night shift than the morning types. Kerkof, Korving, and Lancel (1986) examined morning and evening types during changes in daylight savings time. The authors concluded that morning types showed a delayed alertness rhythm subsequent to the daylight saving time change (i.e., a change in circadian rhythm which is not as severe as the changes associated with rotating shift work.). Foret, Benoit, and Royant-Parola (1982) examined the sleep of vacationing morning and evening types, and discovered that evening types delayed their sleep time by one hour and their arising time by up to two and one half hours. Morning types did not modify their bedtime and awoke only one hour later than usual. These data support the assertion that evening types are more flexible and adaptable than morning types with respect to sleep cycles. 
Mood \& Shift Rotation

\section{Shift Work and Health}

Colquhoun and Folkard (1978) reported that more than one half of the shift workers, compared to $15 \%$ of the day workers, reported health problems related to their work. In addition, when asked if they could continue this type of work, $18.5 \%$ of the shift workers versus $69.3 \%$ of the day workers, said they could do so until retirement. Colquhoun and Folikard concluded that certain individuals may have long lasting psychosomatic and pseudoneurotic reactions to shift work which may endure even after the termination of shift work.

Akerstadt (1980) found that the highest rate of well-being was in the evening shift of both 2 and 3 shift workers. Morning shift was second in workers' ratings of well-being with the night shift rated the lowest. Another study concluded that between $35 \%$ and $50 \%$ of shift workers developed increased irritability, nervousness, and bad tempers which they attributed to shift-work (Thiis-Evenson, 1958). In a longitudinal study by Akerstedt and Torsvall (1978), rotating 3-shift workers who gave up the night shift indicated an improvement in general well-being and a decrease in sleep and mood complaints. Well-being was reported as being affected more negatively while working the night shift (Akerstedt \& Torsvall, 1981). Meers, Maasen, and Verhagen (1978) reported on the subjective health scores of new shift workers after 6 months and found a decrease in their health scores. Interestingly, this same study showed even after 4 years the workers' health scores continued to decrease. Of those workers who had left shift work, 30\% reported doing so because of the disruption in their well- 
Mood \& Shift Rotation

being and / or disturbances in social relationships. Mohan (1969) reported that rotating shift workers had significantly higher neuroticism scores than did day workers and overall, day workers exhibited higher levels of "mental health." Jamal and Jamal (1982) found that subjects in fixed shifts have better motivation, better job performance, and less physical and mental illness, than subjects on rotating shifts. It also has been demonstrated that workers with high neuroticism scores on the Eysenck Personality questionnaire show significantly lower ability to adapt to night shift than workers with "psycho-emotional stability" (Mihailescu, 1977). Furthermore, Anderson (1958) observed nervous disorders in $64 \%$ of rotating shift workers as compared to $25 \%$ of day workers. In addition, $32 \%$ of workers who formerly worked rotating shifts and now worked only days suffered nervous conditions in comparison to $13 \%$ of workers who had never worked rotating shifts.

In contrast, howeve:, other authors have concluded that health is not negatively affected to a significant degree by shift work (Rutenfranz, 1971; Taylor, 1967; Tune, 1969). For example, when Walker and De La Mare (1971) compared shift workers to day workers, they found no significant difference in health risk. However, it should be noted that many of those day workers may have been ex-shift workers, and since this finding was not explored, it may have confounded the outcome. Alter, Bonnet, and Kramer (1971) also failed to find significant differences in mood under lab-initiated sleep conditions constructed to be representative of different work shifts. 
Mood \& Shift Rotation

\section{Length of Sleep}

The length and quality of sleep that shift workers obtain have not been uniform across studies that have considered these variables. For example, Morioka (1969) found that workers on alternating day and night shifts had less sleep than the national average for Japan. Specifically, rotating shift workers averaged 6.5 hours, night shift workers 5.5 hours, while those assigned permanent days averaged 7.5 hours of sleep. Tune (1969) reported that shift workers obtain more sleep than day workers because workers compensated for lost of sleep on their off days. Akerstedt and Torsvall (1978) reported when the night shift was removed, make-up sleep was reduced by 1.5 hours on the workers' off days. The afternoon shift workers compensated by late rising and napping (Akerstedt, Torsvall, \& Gillberg, 1981). However, night shift workers have been found to lose up to 2 to 3 hours of sleep nightly (Akerstedt \& Gillberg, 1979). Akerstedt, Patkai, and Dalgren (1977) reported that permanent night workers have adjusted better to night work and thus exhibit a high degree of alertness. Conversely, split shift workers do not adjust as well when working a short period of night work. Permanent night workers compared to rotating shift workers reported being better adjusted to night work in respect to both the quality and the quantity of their sleep (Dalgren, 1981). When a subjective analysis of recovery after night work was done in the case of 7 day shift rotation, workers complained of considerable degree of fatigue in comparison to morning and evening shifts (Meijman, 1981). Knauth, Landau, Droge, Schwetteck, Widynski, and Rutenfranz (1980) found that the shortest period 
Mood \& Shift Rotation

of sleep, 7 hours, occurred prior to the morning shift. They also suggested there should not be too many successive night shifts and that morning shifts should begin later so to avoid a sleep deficit accumulation within workers. Akerstedt and Torsvall (1981) found that the shortest amount of sleep occurred after the night shift, followed by the morning shift. Of special relevance to this study, Breithaupt, Hildebrandt, Dohre, Josch, Sieber, and Werner (1978) concluded that morning types reacted with a sleep deficit to late shift work, and exhibited more pathological symptoms. Additionally, Breithaupt et al. stated that because evening types have a delayed circadian rhythm, they were inherently less vulnerable to delayed sleep.

Overall, the literature cited suggests that morning and evening types are affected differentially by shift work. However, much of the relevant literature is in conflict. This study was designed to help clarify the conflicting research by examining the relationship between morningness / eveningness and shift work adaptability as reflected in mood. In addition, this study was designed to measure both sleep length and sleep satisfaction as a function of adjustment to work shift by both morning types and evening types.

\section{Method}

\section{Research Participantís}

A group of 50 nurses from a Bay Area hospital was asked to participate voluntarily in the study. The nurses ranged in age from 23 to 60 years. They worked a Day / Night or Day / Evening rotation. The rapidity of the 
Mood \& Shift Rotation

rotations varied from every $2,4,8$ weeks to every 6 months. The day shifts were either 6:45 A.M. to 3:15 P.M., or 8 A.M to 4:30 P.M. The evening shifts were either 2:45 P.M. to 11:15 P.M., or 4 P.M. to 12:30 A.M. The night shifts were either 10:45 P.M. to 7:15 A.M., or 12 A.M. to 8:30 A.M. Fifty subjects took the Ostberg Scale (Horne \& Ostberg, 1976) to determine morningness or eveningness. Those subjects $(n=27)$ with an score of $\leq 53$ were classified as morning types, and were included in the morningness group, while those subjects $(n=23)$ with a score $>53$ were classified as evening types, and were included in the eveningness group.

\section{Measures}

\section{Morning and Evening Types}

The Oistberg Scale (Horne \& Ostberg, 1976) is a self-report measure most commonly used to delineate the morningness-eveningness dimension. It takes approximately 6-8 minutes to complete and consists of 19 questions, some of which require an answer on a time scale. For this study, subjects were given a forced choice format that excluded the "do not know / cannot decide" categories. A copy of the modified Ostberg Scale, used in this study is attached as Appendix 1.

Mood

The Profile of Mood State test (POMS) was used to assess mood. The POMS is a standardized 65 item self-report questionnaire divided into six scales: tension / anxiety, depression / dejection, anger / hostility, vigor / activity, fatigue / inertia, confusion / bewilderment. Every item has five possible answers ranging from "not at all" to "extremely." Descriptive 
Mood \& Shift Rotation

words such as guilty, lively, angry, weary etc. are used to articulate mood states. Each subject filled out the POMS scale five times on the day shift and five times on the night / evening shift. The POMS requires 2 to 5 minutes to complete.

\section{Sleep Duration}

The questionnaire designed especially for this study to measure sleep length and satisfaction is attached as Appendix 3. Each subject was asked to complete this questionnaire at the same times that he or she completed the POMS scale. The questionnaire asked the specific times the subjects retired and arose. The subjects were to indicate any naps taken prior to working and were asked to rate their sleep as satisfactory or nonsatisfactory.

\section{Design}

Each subject received an envelope packet that included (a) The Ostberg Scale, (b) ten POMS tests and (c) ten Sleep Data Questionnaires. Subjects were instructed to read each question of the Ostberg Scale carefully before responding, and to answer the questions independently of each other, without rechecking their answers. For questions that involved the time scale, the subjects were instructed to place a cross $(\mathrm{X})$ at the appropriate point along the scale.

Each subject was instructed in how to self-administer the POMS scale. Subjects were asked to fill in what shift they worked at the top of the scale. Each subject was asked to fill out the POMS at the end of his or her working period. Subjects were also told to respond to the POMS without much 
deliberation and that the first response should be left unchanged. The POMS was to be completed five times on each shift (day / night or day / evening) and not on off days.

The sleep questionnaire took approximately one minute to complete. It, too, was completed for a total of ten times. Subjects were asked to complete this questionnaire at the same time they filled in the POMS.

Subjects were assured that all of their responses would be held in confidence.

\section{Results}

The six POMS scales were scored for each of the $\mathbf{5 0}$ subjects. For each subject there was a total of ten scores on each of the six scales of the POMS. These responses on the POMS scale were scored five times on the day shift and five times on the night/ evening shift. The means and standard deviations were calculated for each of the scales during each shift period for both the morning and evening type groups. These values are listed in Table 1.

\section{The Test of Hypothesis 1}

This hypothesis predicts morning types will score significantly higher than evening types while working the evening / night shifts on five scales (confusion, fatigue, tension, anger, depression) of the POMS. Conversely, while working the morning shift, evening types will score significantly higher on the same scales than morning types. By inspecting Table 1, the pattern of means is in the opposite direction from this prediction. With the exception of the POMS fatigue scale, morning types scored lower than 
Mood \& Shift Rotation

14

Table 1

Means and Standard Deviations for Morning and Evening Types

Response to Scales of the POMS during Dav and Evening Shifts

\begin{tabular}{lcccccccc} 
& \multicolumn{4}{c}{ Morning Types } & \multicolumn{4}{c}{ Evening Types } \\
POMS Scale & \multicolumn{2}{c}{ Days } & \multicolumn{2}{c}{ Nights } & \multicolumn{2}{c}{ Days } & \multicolumn{2}{c}{ Nights } \\
& M & SD & M & SD & M & SD & M & SD \\
\hline \multirow{2}{*}{ Confusion } & 33.7 & 21.4 & 51.7 & 30.3 & 45.0 & 28.7 & 57.0 & 36.5 \\
Fatigue & 61.8 & 43.2 & 97.6 & 48.4 & 84.2 & 52.9 & 91.4 & 63.1 \\
Tension & 52.9 & 29.8 & 71.0 & 34.2 & 76.8 & 36.9 & 74.0 & 36.2 \\
Anger & 32.8 & 43.0 & 49.9 & 55.1 & 50.6 & 42.9 & 55.5 & 55.5 \\
Depression & 31.0 & 42.9 & 49.9 & 49.0 & 55.0 & 64.5 & 59.0 & 76.0 \\
Vigor & 150.2 & 49.1 & 93.4 & 60.6 & 139.9 & 44.7 & 106.1 & 42.3
\end{tabular}


Mood \& Shift Rotation

evening types while working the night shift. This pattern of mean differences was not the pattern predicted by hypothesis 1 . This hypothesis was further tested by computing separate two (evening vs. morning types) by two (morningness score vs. eveningness score) factor ANOVAs for each of the five POMS scales with repeated measures on the second factor. Inspection of Tables 2-7 reveal that with the possible exception of tensionanxiety, none of the main effects for Type were significant. Thus, the conclusion is that hypothesis 1 is not supported.

The Test of Hypothesis 2

Hypothesis 2 states that while working nights / evenings, morning types will score lower than evening types in the vigor scale. Evening types will score significantly lower than morning types while working days. In general, evening types will be less disrupted by evening / night work.

This hypothesis was tested by computing a two--tailed $t$ test between the responses obtained from the morning and evening types to the vigor scale during the night shift. While the means for this scale during the night shift are in the predicted direction (see Table 1), the difference between them was not significant $(t(98)=.89, \mathfrak{p}>.05)$. Furthermore, a two (evening vs. morning type) by two (morning vs. evening / night score) factor ANOVA, with repeated measures on the second factor, for the POMS vigor scale revealed non-significant results (see Table 7).

The Test of Hypothesis 3

This hypothesis states that the length of sleep while working nights / evenings will be affected more in morning types than evening types. 
Mood \& Shift Rotation

16

\section{TABLE 2}

Confusion-Bewilderment Scale

\begin{tabular}{lrrrrr} 
SOURCE & \multicolumn{1}{c}{ SS } & DF & MS & F & P \\
Type (Morn./ Eve.) & 1694.470 & 1 & 1694.470 & 1.951 & N.S. \\
Time (Days / Nights) & 5776.000 & 1 & 5776.000 & 6.651 & $<.01$ \\
Type X Time & 230.087 & 1 & 230.087 & .265 & N.S. \\
Residual & 83372.283 & 96 & 868.461 & & \\
Total & 91072.840 & 99 & 919.928 & & \\
E $(1,96)=6.65 \mathrm{n}<.01$ & & & & &
\end{tabular}


Mood \& Shift Rotation

17

TABLE 3

Fatigue-Inertia Scale

$\begin{array}{lrrrrr}\text { SOURCE } & \text { SS } & \text { DF } & \text { MS } & \text { F } & \text { P } \\ \text { Type (Morn./ Eve.) } & 1628.716 & 1 & 1628.716 & .605 & \text { N.S. } \\ \text { Time (Days / Nights) } & 12746.410 & 1 & 12746.410 & 4.735 & <.05 \\ \text { Type X Time } & 5083.193 & 1 & 5083.193 & 1.888 & \text { N.S. } \\ \text { Residual } & 258431.871 & 96 & 2691.999 & & \\ \text { Total } & 277890.190 & 99 & 2806.972 & & \\ \text { F }(1,96)=4.7, \mathbb{R}<.05 & & & & & \end{array}$


Mood \& Shift Rotation

18

TABLE 4

Tension-Anxiety Scale

$\begin{array}{lrrrrr}\text { SOURCE } & \text { SS } & \text { DF } & \text { MS } & \text { F } & \text { P } \\ \text { Type (Morn./ Eve.) } & 4506.054 & 1 & 4506.054 & 3.860 & <.06 \\ \text { Time (Days / Nights) } & 1814.760 & 1 & 1814.760 & 1.554 & \text { N.S. } \\ \text { Type X Time } & 2741.551 & 1 & 2741.551 & 2.348 & \text { N.S. } \\ \text { Residual } & 112077.675 & 96 & 1167.476 & & \\ \text { Total } & 121140.040 & 99 & 1223.637 & & \\ \text { F }(1,96)=3.86, \mathfrak{p}<.06 & & & & & \end{array}$


Mood \& Shift Rotation

19

TABLE 5

Anger-Hostility Scale

\begin{tabular}{lrrrrr} 
SOURCE & SS & DF & \multicolumn{1}{c}{ MS } & F & P \\
Type (Morn./ Eve.) & 3395.482 & 1 & 3395.482 & 1.330 & N.S. \\
Time (Days / Nights) & 3329.290 & 1 & 3329.290 & 1.304 & N.S. \\
Type X Time & 923.028 & 1 & 923.028 & .362 & N.S. \\
Residual & 245073.910 & 96 & 2552.853 & & \\
Total & 252721.710 & 99 & 2552.745 & &
\end{tabular}


Mood \& Shift Rotation

20

TABLE 6

Depression-Dejection Scale

$\begin{array}{lrrrrr}\text { Source } & \text { SS } & \text { DF } & \text { MS } & \text { F } & \text { P } \\ \text { Type (Morn./ Eve.) } & 6951.127 & 1 & 6951.127 & 1.944 & \text { N.S. } \\ \text { Time (Days / Nights) } & 2561.708 & 1 & 2561.708 & .716 & \text { N.S. } \\ \text { Type X Time } & 2293.618 & 1 & 2293.618 & .641 & \text { N.S. } \\ \text { Residual } & 343239.921 & 96 & 2375.416 & & \\ \text { Total } & 354867.840 & 99 & 3584.534 & & \end{array}$


Mood \& Shift Rotation

21

\section{TABLE 7}

Vigor-Activity Scale

$\begin{array}{lrrrrl}\text { SOURCE } & \text { SS } & \text { DF } & \text { MS } & \text { F } & \text { P } \\ \text { Type (Morn./ Eve.) } & 35.082 & 1 & 35.082 & .014 & \text { N.S. } \\ \text { Time (Days / Nights) } & 53361.000 & 1 & 53361.000 & 21.211 & <.001 \\ \text { Type X Time } & 3283.710 & 1 & 3283.710 & 1.305 & \text { N.S. } \\ \text { Residual } & 241507.768 & 96 & 2515.706 & & \\ \text { Total } & 298187.560 & 99 & 3011.996 & & \\ \text { F }(1,96)=21.21, \text { p }<.001 & & & & & \end{array}$


Hypothesis 3 was tested by using the sleep length data derived from the sleep-shift work questionnaire. First, a day shift sleep length was derived for each subject by computing his or her average sleep lengths during this period. Next, a night / evening shift sleep length was derived by computing each subject's average sleep length during this shift period. The means and standard deviations calculated for each shift period for the morning and evening groups are presented in Table 8. Also included in this table are the percentages of those who reported satisfaction with their sleep during each period. A total of 28 subjects ( $\underline{n}=16$ morning types; $\underline{n}=12$ evening types) completed the sleep questionnaire.

Hypothesis 3 predicts the sleep of morning types will be more affected by shift change than the sleep of evening types. The data summarized in Table 8 provide ambiguous support for this prediction. While the mean difference between the day and evening shifts is greater for evening types (1.4 hours and .9 hours, respectively), the difference observed for morning types between these shifts is more significant $(t(26)=4.29, \mathrm{p}<.001)$ than the mean difference for the evening types $(t(26)=2.55, \mathrm{p}<.02)$. Furthermore, the sleep satisfaction between shifts is four times greater for the morning type (28\%) than it is for evening types (7\%). Thus it is relatively clear that although they slept longer and experienced less change in their sleep length when changing shifts, morning types perceived more disruptions in their sleep than did evening types.

Discussion

Overall, this study fails to support hypotheses 1 and 2 with regard to the 
Mood \& Shift Rotation

Table 8

Means and Standard Deviations for Hours of Sleep in Morning and Evening Types, and Sleep Satisfaction Rating

\begin{tabular}{|c|c|c|c|c|}
\hline \multirow[t]{2}{*}{ Shift } & Type & \multicolumn{2}{|c|}{ Hours of Sleep } & \multirow[t]{2}{*}{ Satisfaction \% } \\
\hline & & M & $\mathrm{SD}$ & \\
\hline \multirow[t]{2}{*}{ Day } & Morning & 7.1 & 0.6 & $88 \%$ \\
\hline & Evening & 6.3 & 1.5 & $70 \%$ \\
\hline \multirow[t]{2}{*}{ Night } & Morning & 8.0 & 0.5 & $60 \%$ \\
\hline & Evening & 7.7 & 1.1 & $63 \%$ \\
\hline
\end{tabular}


Mood \& Shift Rotation

24

predictions made for the six scales of the POMS. It appears that morningness and eveningness, as defined by the Ostberg Scale, may be of little value in predicting workers' adaptability to a rotating shift schedule. However, in some of the mood dimensions this study concurs with Ostberg (1973) when he stated that night shift is the most difficult shift to which to adapt. In examining the main effect for shift time, both types were significantly more disrupted on the night / evening shift than the day shift, on these POMS scales: confusion $(t(98)=2.58, \mathfrak{p}<.011$, fatigue $(t(98)=2.17, \mathrm{p}<.05)$, and vigor $(\mathrm{t}(98)=4.62, \mathrm{p}<.05)$. Furt $\mathrm{l}$ : ermore, morning types were significantly more disrupted during night / evening shifts on tension $(t(52)=-2.08, p<.05)$.

It is interesting to notf, that there were no significant results for either type or time in the depression and anger scale. Although the POMS is thought to assess current mood states, one might speculate that these POMS scales measure personality traits that are relatively unaffected by shift work.

Predicting the adaptability of the employees to shift work hopefully would encourage productivity as well as decrease the potential for hazardous situations. By using a larger sample size and more sensitive measurements it may be shown that morning types are generally more disrupted in mood while working nights and evenings. Such data might indicate that morning types have a more autonomous circadian rhythm than evening types.

More research is warranted both in the evaluation of shift workers' mood 
states and in the construction of a more definitive scale to delineate between morning and evening types. Folkard, Monk, and Lobban (1978) suggested the need for a questionnaire that takes into consideration the worker's ability to overcome drowsiness, flexibility of sleep habits, as well as the ability to adjust bodily rhythms. According to the data gathered in this study, the Ostberg Scale does not adequately differentiate individual differences between morning and evening types. These results may be related to an earlier study by Foret, Benoit and Royant-Parola (1982). They failed to find significant differences in temperature peak time between morning and evening types, and as a result concluded that differences found between Horne and Ostberg "types" are not based on the subjects' temperature curve. However, they did conclude that morning and evening types differed in alertness peak time, but they failed to validate the hypothesis (Kleitman et al.,1983) that level of performance was related to body temperature.

The method with which the Ostberg Scale was used in this study may have yielded the inconclusive results. As it was originally conceived, the Ostberg scale was designed to divide subjects into five categories (a) definitely morning type, (b) moderately morning type, (c) neither morning nor evening type, (d) moderately evening type, and (e) definitely evening type. The neither morning nor evening type category in some studies accounts for more than a majority of the subjects. For example in Folkard, Monk, and Lobban's 1978 study, 20 subjects were grouped in the neither morning nor evening type category, as compared to 7 subjects grouped in 
Mood \& Shift Rotation

26

the morning type category, and 8 subjects grouped in the evening type category.

In this study these categories were not used, thus possibly confounding the outcome. Of the 50 subjects classified, only one was a definite morning type; the remaining subjects were distributed in the moderately morning type, moderately evening type, and neither morning nor evening type categories. Thus a larger sample size of definitely morning types and definitely evening types may have yielded significant results. If a more equal distribution of subjects throughout the categories is necessary for significance, then one implication may be that the Ostberg Scale is not of great value in predicting mood changes associated with shift work because too many people who do not fit into the extreme categories by the scores of the Ostberg Scale would be excluded.

Another variable which was not taken into consideration for this study were the subjects' ages. Akerstadt (1980) concluded that individuals over 45 years reported a decline in well-being while working the night shift. The majority of the subjects in this study were in their late 20's and 30's. It may be postulated that individual differences are difficult to cull from a population. These differences may become more specific as the subject ages, and younger subjects may have more adaptable or labile parameters.

Hypothesis 3 was partially supported by these data; that is, morning types reported more satisfaction with their sleep while working days than did evening types. In addition, morning types were less satisfied with their sleep while working nights / evenings than evening types. It is interesting 
Mood \& Shift Rotation

to note that the mean hours for sleep was less when these subjects worked day shifts than when they worked the nights / evenings rotation (i.e., 7.3 hours vs. 7.9 hours). This result confirms Knauth et al. (1980) findings that morning workers obtained the least amount of sleep. However, other studies (e.g., Morioka, 1969; Akerstadt \& Torsvall, 1981) have shown that night workers tended to be sleep deprived. It may be of value here to consider the time that morning shifts begin, and thereby avoid very early shift starts in order to increase sleep length.

In summary, there may be specific individual differences in ability of morning and evening types to adapt to shift work. However, with the exception of sleep, this study failed to find significant data to support this thesis. Nevertheless, morningness / eveningness may still prove to be a mechanism useful in delineating personality types important to other behaviors critically affected by shift work. However, additional research is warranted to elaborate further these variables. 
Mood \& Shift Rotation

REFERENCES

Akerstedt, T. (1980). Inter-individual differences in adjustment to shiftwork. In W. P. Colquhoun \& J. Rutenfranz (Eds.) Studies of Shiftwork (pp. 259-270). London: Taylor and Francis

Akerstedt, T., \& Gillberg, M. (1979). The circadian pattern of unrestricted sleep and its relation to body temperature, hormones, alertness. Paper presented at a Symposium sponsored by the National Institute for Occupational Safety and Health and Office of Naval Research. Variations in work-sleep schedules: Effects on health and performance. San Diego, September 19-23.

Akerstedt, T., Patkai, P., \& Dalgren, K. (1977). Field studies of shiftwork: temporal patterns in psychophysiological activation in workers alternating between night and day work. Ergonomics, 20, 621-631.

Akerstedt, T., \& Torsvall, L. (1978). Experimental changes in shift schedules -- their effects on well-being. Ergonomics, 21, 840-856.

Akerstedt, T., \& Torsvall, L. (1981). Shift-dependent well-being and individual differences. International Archives of Occupational and Environmental Health, $\underline{48}$, 265-272. 
Mood \& Shift Rotation

Akerstedt, T., Torsvall, L., \& Gillberg, M. (1981). Napping and irregular work hours. Sleep Research, 10, 132.

Alter, J., Bonnet, M., \& Kramer, M. (1981). Effects of irregular vs. regular sleep schedules on performance, mood, and body temperature. Sleep Research, 10, 122.

Andersen, E. J. (1958). The main results of the Danish medico-psychosocial investigation of shift workers. Proceedings of the XII International Congress on Occupational Health, Helsinki, 1-6 July 1957, pp. 135-136.

Breithaupt, H., Hildebrandt, G., Dohre, D., Josch, R., Sieber, U., \& Werner, M. (1978). Tolerance of shift of sleep, as related to the individual's circadian phase position. Ergonomics, 21, 767-774.

Colquhoun, W. P., \& Folkard, S. (1978). Personality differences in body temperature rhythm, and their relation of its adjustment to night work. Ergonomics, 21, 811-817.

Dalgren, K. (1981). Adjustment of circadian rhythms and EEG functions to day and night sleep among permanent night and rotating shift workers. Psychophysiology, 18, 381-391. 
Mood \& Shift Rotation

Folkard, S., Monk, T., \& Lobban, M. (1978). Individual differences, and personality factors, in adjustment to shift work. Ergonomics, $\underline{21}$, 785-99.

Foret, J., Benoit, O., \& Royant-Parola, S. (1982). Sleep schedules and peak times of oral temperature and alertness in morning and evening types. Ergonomics, 25, 821-827.

Horne, J. A., \& Ostberg, O. (1976). A self-assessment questionnaire to determine morningness-eveningness in human circadian rhythms. International Journal of Chronobiology, 4, 97-110.

Horne, J. A., \& Ostberg, O. (1977). Individual differences in human circadian rhythm. Biological Psychology, 5, 179-190 .

Jamal, M. \& Jamal, S. (1982). Work and nonwork experiences of employees on fixed and rotating shifts: An empirical study. Journal of Vocational Behavior, 20, 282-293.

Kerkhof, G., Korving, H., \& Lancel, M. (1986). The circadian system response to morning type and evening type subjects to daylight savings time. Sleep Research, 12, 367. 
Kleitman, N. (1963). Sleep and Wakefulness (2nd Ed.). Chicago: University of Chicago Press.

Knauth, P., Landau, K., Droge, C., Schwetteck,M., Widynski, J., \& Rutenfranz, J. (1980). Duration of sleep depending on the type of shiftwork. Occupational and Environmental Health, 46, 167-177.

McNair, D. M., Lorr, M., \& Droppleman, L. (1971). Manual for the Profile of Mood States. San Diego: Educational and Industrial Testing Service.

Mecacci, L. \& Zani, A. (1983). Morningness-eveningness preferences and sleep-waking diary data of morning and evening types in students and worker samples. Ergonomics, 26, 1147-1153.

Meers, A., Maasen, A., \& Verhagen, P. (1978). Subjective health after six months and after four years of shift work. Ergonomics, 21, 857-859

Meijman, T. F. (1981). Subjective analysis of recovery after night work in the case of shift rotation ( 7 days). Travail Human, 44, 315-323.

Mihailescu, V. (1977). The psychology of worry and renouncement, the psychology of injurious war: Problems of daily life Bollettino di Psicologia Applicata, pp. 141-142, 19-37. 
Mood \& Shift Rotation

32

Mohan, R. (1969). 3-shift rotation and mental health. Indian Journal of Clinical Psychology, 10, 369-372.

Morioka, M. (1969). Physiological burden to shiftwork: A study of their sleeping hours. Paper presented at the Meeting of the XVIth International Congress on Occupational Health, Tokyo.

Ostberg, O. (1973). Circadian rhythm of food intake and oral temperature in "morning" and "evening" groups of individuals. Ergonomics, 16, 203-209.

Patkai, P. (1970). Diurnal differences between habitual morning workers and evening workers in some psychological-physiological functions. Report from the Psychology Laboratories of Stockholm University, No. 311

Patkai, P. (1971a). Inter-individual differences in diurnai variations in alertness, performance, and adrenaline excretion. Acta Physiologica Scandinavica, 81, 35-46.

Patkai, P. (1971b). The diurnal rhythm of adrenaline secretion in subjects with different working habits. Acta Physiologica Scandinavica, 81, 30-31. 
Mood \& Shift Rotation

33

Rutenfranz, J. (1971). Probleme der Schichtarbeit. Werksarztliches, $2 / 3$, 1-27.

Taub, J., Hawkins, D., \& Van de Castle, R. (1978). Temporal relationships of napping behavior to performance, mood states, and sleep physiology. Sleep Research, 7, 164.

Taylor, P.J. (1967). Shift and day work: a comparison of sickness, absence, lateness and other absence behaviors at an oil refinery from 1962-1965. British Journal of Industrial Medicine, 24, 93-102.

Tepas, D. \& Mahan, R. (1986). Work shift preference, morningnesseveningness, and sleep. Sleep Research, 15, 287.

Thiis-Evenson, E. (1958). Shift work and health. Industrial Medicine and Surgery, 27, 493-497.

Tune, G, S., (1969). Sleep and wakefulness in a group of shift workers. British Journal of Industrial Medicine, 26, 54-58.

Walker, J, \& De La Mare, G. (1971). Absence from work in relation to length and distribution of shift hours. British Journal of Industrial Medicine, 28, 36-44. 
Mood \& Shift Rotation

34

Winget, C., DeRoshia, C., Markley, C. \& Holley, D. (1984). A review of human physiological and performance changes associated with desynchronization of biological rhythms. Aviation, Space, \& Environmental Medicine, 55, 1085-1096. 


\section{PLEASE NOTE:}

Copyrighted materials in this document have not been filmed at the request of the author. They are available for consultation, however, in the author's university library.

These consist of pages:

35-39, Appendix 1, Horne and 0stberg Sca7e 
Mood \& Shift Rotation

40

APPENDIX 2

SLEEP DATA QUESTIONNAIRE

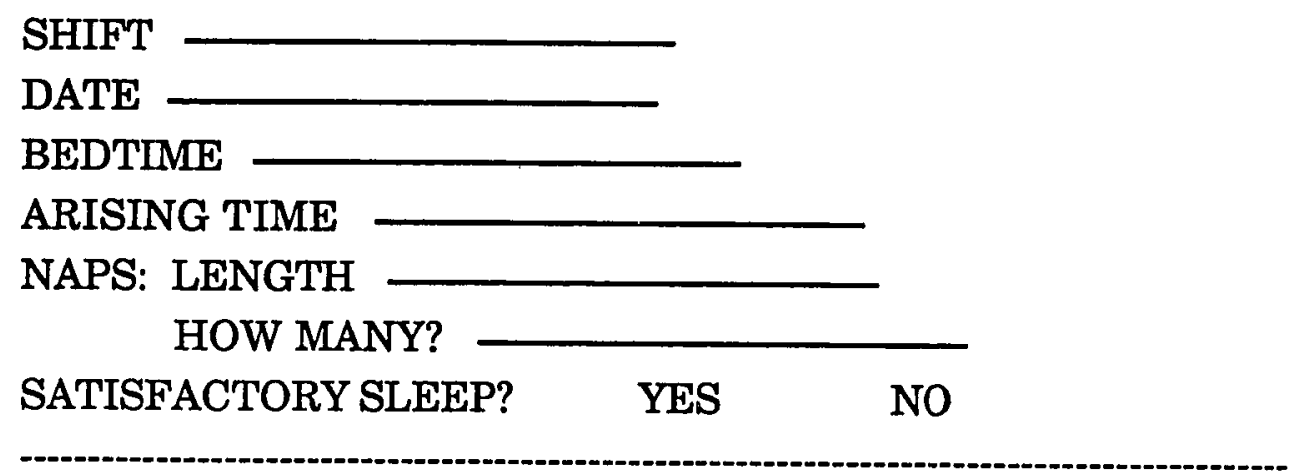

SLEEP DATA QUESTIONNAIRE

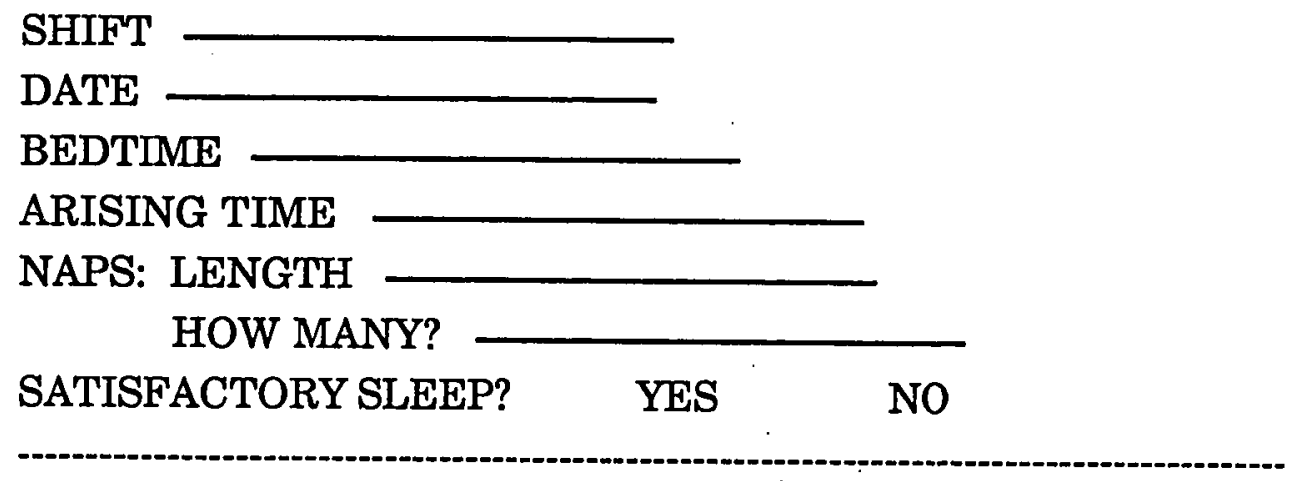

SLEEP DATA QUESTIONNAIRE

SHIFT

DATE

BEDTIME

ARISING TIME

NAPS: LENGTH

HOW MANY?

SATISFACTORY SLEEP?

YES

NO 